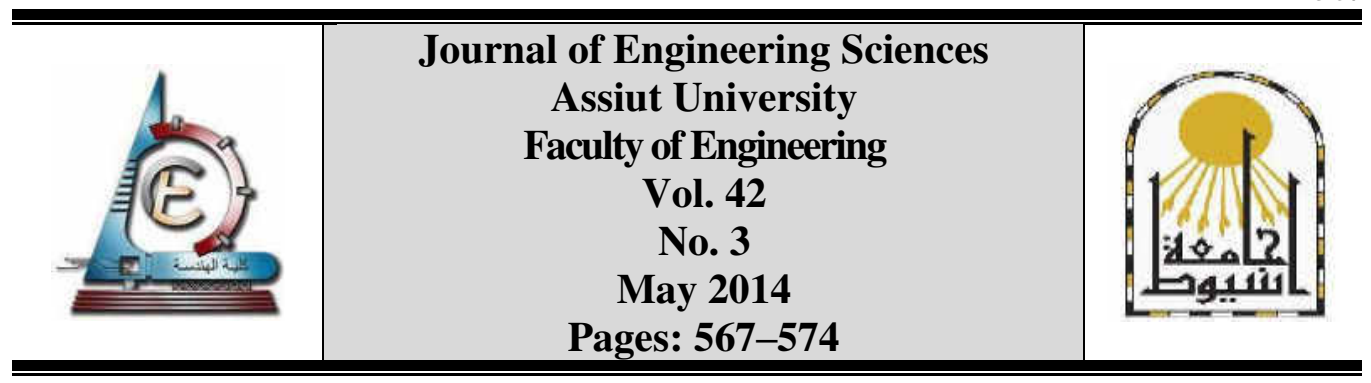

\title{
EFFECT OF AGGREGATE GRADATION AND TYPE ON HOT ASPHALT CONCRETE MIX PROPERTIES
}

\author{
Afaf A. H. M. \\ Civil Eng. Dep., Faculty of Eng., Minia University
}

Received 17 February 2014; revised 28 February 2014; accepted 4 March 2014

\begin{abstract}
Mineral aggregates make up 90 to $96 \%$ of a HMA mix by weight or approximately 75 to $85 \%$ by volume. The properties of the mineral aggregates have significant affects in performance of our roadways which offers the possibility of investment in these properties towards resisting different ranges of external applied loads and environmental conditions. Therefore, aggregate characteristics deeply affect the performance of asphalt pavements. Gradation is one of the important characteristics of aggregates affecting permanent deformation of hot mix asphalt. The objective of this research is to investigate the impact of aggregate gradation variations on various properties of asphalt concrete mixtures. Fine, medium and coarse gradation mixtures for different aggregate types were tested to investigate the effects of variation in the aggregate types and gradation on mix properties. The asphalt contents of the mixes were maintained at the job mix design contents.

Properties investigated were, Marshall Stability, Marshall Flow, unit weight, air voids, and voids in mineral aggregate. Analysis of the considering different aggregate type data revealed that the finecoarse and coarse-fine gradation variations had the greatest impact on mix.

The research program concentrated on the Marshall Design criteria for bituminous mixes. The results indicated that optimum asphalt content (OAC) is different due to aggregate type A coarse grading with $25 \mathrm{~mm}$ maximum size is found to give the most satisfactory result from the stand point of stability, stiffness, and voids characteristics. Test results reveal that the bituminous concrete with WCA can give satisfactory results when they are constructed using coarse gradation.
\end{abstract}

Keywords: Bituminous concrete, Gradation of aggregate, Marshall Design criteria.

\section{Introduction}

Asphalt concrete $(\mathrm{AC})$ is a heterogeneous material that consists of asphalt cement, natural or artificial aggregate, mineral filler, additives and air voids. Aggregate comprise the vast bulk of paving mixture and therefore, exert significant influence on the resulting engineering properties of the structure. Coarse aggregate is the material, which is substantially retained on No. 4 sieve $(2.365 \mathrm{~mm})$. Generally, the asphalt concrete mixture contains from 35-65 percent of coarse aggregate for a nominal maximum size of $19.0 \mathrm{~mm}$. This content normally gives a suitable texture for a heavily trafficked road (ASTM, 2003). [1] 
Afaf A. H. M., Effect of aggregate gradation and type on hot asphalt concrete......

Aggregate properties can affect mix properties in different ways. For example, if the aggregates used are weak they may disintegrated easily under the action of Marshall hammer during the mix design process. Consequently, fines and filler content in the mix are increased leading possibly, to a Marshall stability being higher than usual [2].

The factor that is usually noticed as the most effective parameter causing rutting is the characteristics of aggregates. Ahlrich [3] also mentioned that HMA properties are highly affected by their aggregate characteristics. Button et al. [4] have found nine possible factors cause rutting, but stated that the aggregate characteristics is the primary material quality factor influencing rut susceptibility. Stakston and Bahia [5] also have indicated that rut resistance is "highly dependent on aggregate grading", and that mixes made with the best possible materials would fail without a proper gradation.

Gandhi and Lytton [6] investigated large number of aggregate tests and whether these tests can be used as indicators of performance of asphalt concrete mixes.

Bissada [7] reported that, resistances to compaction of bituminous mixes are affected by mix variables (filler content, binder content and type of asphalt binder). Higher the resistance of the mix to compaction, higher it's measured stiffness value and consequently better resistance to permanent deformation performance is expected in the pavement. Higher the percent of fines in the mix, higher is the measured stiffness of mix at a lower value of resistance to compaction.

Bose [8] reported that, permanent strain decreased with increased aggregate size in large stone mixes. Large size aggregate has led to lower binder content, high density, satisfying voids in mineral aggregate. However, no correlation of aggregate properties with asphalt concrete was attempted [9]. El-Basyouny and Mamlouk in 1999 evaluated the effect of aggregate gradation on the rutting potential [10]. They found that both the aggregate gradation and aggregate nominal size affected the rut depth for pavement section. Mixtures prepared using aggregate gradation passing below the restricted zone (on the Super pave gradation chart) had better resistance to rutting as compared to those made from aggregates with gradation passing through or above the restricted zone [10,11]. This means that coarser gradations are expected to perform better than finer gradation.

Therefore, this study focuses on the effect of aggregate type and gradation more in detail and investigates the effect of coarse and fine gradation for different aggregate on Marshal properties by dividing the gradation limits into different parts (upper, middle and lower gradation).

Fine, medium and coarse gradation mixtures were tested and the effects of variation in the aggregate gradation on mix properties were investigated.

\section{Objective and test plan}

The objective of this study was to evaluate the effect of aggregate type and gradation on Marshall Properties for HMA mixture (specific gravity, stability, flow, and air voids). To accomplish this, various mixtures were compacted with optimum asphalt content and three different gradation types.

The same compactive effort 50 blows/face as a medium traffic loading was used to determine their volumetric and performance-related properties. In order to consider a range of mixtures, three blends of fine, medium and coarse gradations limited by the ASTM specification for gradation were used and shown in Figure 1. 
JES, Assiut University, Faculty of Engineering, Vol. 42, No. 3, May2014, pp. 567-574

\section{Laboratory study and test results}

\subsection{Materials}

\subsubsection{Bitumen properties}

The binder material of 60-70 penetration grade bitumen which commonly used in the region was selected for this research. The bitumen properties were evaluated by various laboratory tests, which are demonstrated in the Table 1.

Table 1.

Binder Properties

\begin{tabular}{|l|l|l|}
\hline \multicolumn{1}{|c|}{ Experiment } & \multicolumn{1}{c|}{ Value } & \multicolumn{1}{c|}{ Standard No. } \\
\hline Penetration Grade at $25^{\circ} \mathrm{C}, 1 / 10 \mathrm{~mm}$ & 66 & ASTM D5 \\
\hline Softening point $\left({ }^{\circ} \mathrm{C}\right)$ & 62 & ASTM D 36 \\
\hline Specific Gravity & 1.012 & ASTM D70 \\
\hline Flash \& Fire point $\left({ }^{\circ} \mathrm{C}\right)$ & $295 / 320$ & ASTM D 92 \\
\hline ductility value $(\mathrm{cm})$ & 100 & ASTM D 113 \\
\hline Kinematic Viscosity (centi Stokes) $60^{\circ} \mathrm{C}$ & 425 & ASTM D2170 \\
\hline
\end{tabular}

\subsubsection{Aggregates}

Aggregate is the major structural framework of asphalt mixture to absorb and control different stresses on the pavement. The aggregates used were subjected to a number of tests. These tests were as follows:

1) Specific gravity (ASTM C 127, 128-84).

2) Water absorption (ASTM C 127, 128-84).

3) Los Angeles abrasion test (ASTM C 535-81).

4) Sand equivalent (ASTM D 2419-79).

5) Soundness (using sodium sulphate) (ASTM C 88-83).

6) Crushing value (B.S. 812: Part 3, 1975).

Table 2 shows different properties of these aggregates which are crushed limestone. The sieve diagram for wearing course is also presented in Figure 1.

Table 2.

Aggregate properties

\begin{tabular}{|c|l|l|l|l|}
\hline \multirow{2}{*}{ Experiment } & \multicolumn{3}{|c|}{ Value } & \multirow{2}{*}{ Standard No. } \\
\cline { 2 - 4 } & $\begin{array}{l}\text { Lime } \\
\text { stone }\end{array}$ & Dolomite & Basalt & \\
\hline Water Absorption \% & 1.61 & 1.48 & 0.27 & (ASTM C 127, 128-84). \\
\hline specific gravity & 25 & 2.74 & 2.92 & (ASTM D 2419-79). \\
\hline Soundness \% & 4.03 & 6.5 & 9.85 & (ASTM C 88-83). \\
\hline Apparent specific gravity & 2.57 & 2.68 & 2.72 & (ASTM C 127, 128-84). \\
\hline LA Abrasion loss & 29.5 & 18.7 & 14.5 & (ASTM DC-131) \\
\hline
\end{tabular}

\subsection{2 .1. Aggregate Gradation}

Aggregate gradations were selected with a nominal size of $19 \mathrm{~mm}$ based on The Asphalt Institute Manual Series "Principles of Construction of Hot-Mix Asphalt Pavements "No.22 MS-22 (1983). According to the failure mechanisms (Rutting), the gradations should be limited between upper limit and lower limit based on the $19 \mathrm{~mm}$ nominal maximum aggregate size. In this study the gradation range divided into three variations that form a band (Fig. 1). 


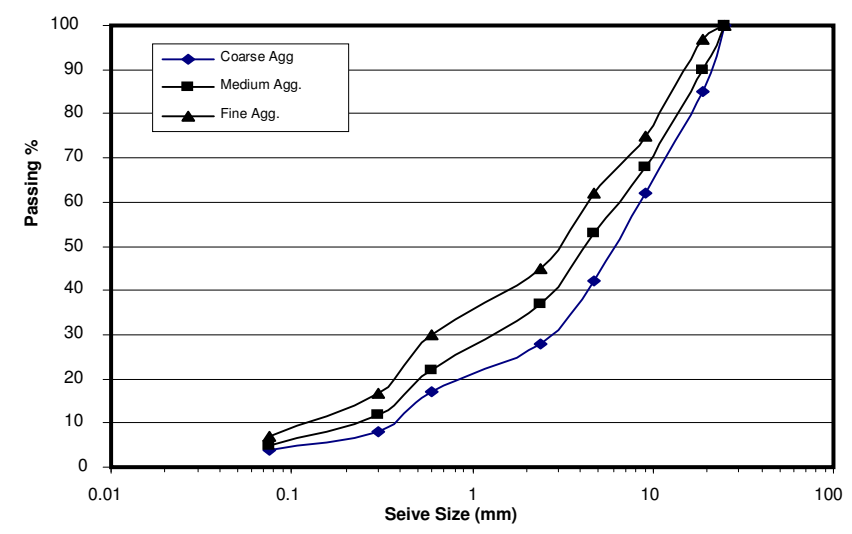

Fig. 1. Three blends of fine, medium and coarse gradations

In order to compare each of variations, the medium gradation of each variation were chosen from sieve diagram. Table 3 shows the percentage of passing for each variation (fine gradation, medium gradation and coarse gradation bands).

Table 3.

Passing Percentage for fine, medium and coarse gradations blends

\begin{tabular}{|c|c|c|c|c|}
\hline \multirow{2}{*}{$\begin{array}{c}\text { Sieve size } \\
\text { Mm }\end{array}$} & \multicolumn{4}{|c|}{ Percent passing } \\
\cline { 2 - 5 } & coarse gradation & medium gradation & fine gradation & specification \\
\hline $25 \mathrm{~mm}(1$ in. $)$ & 100 & 100 & 100 & 100 \\
\hline $19 \mathrm{~mm}(0.75 \mathrm{in})$. & 85 & 90 & 97 & $80-100$ \\
\hline $9 \mathrm{~mm}(0.375$ in. $)$ & 62 & 68 & 75 & \\
\hline $4.75 \mathrm{~mm}(\# 4)$ & 42 & 53 & 62 & \\
\hline $2.36 \mathrm{~mm}(\#)+8)$ & 28 & 37 & 45 & \\
\hline $0.60(\# 25)$ & 17 & 22 & 30 & \\
\hline $0.3 \mathrm{~mm}(\# 50)$ & 8 & 12 & 16.7 & \\
\hline $0.075 \mathrm{~mm}(\# 200)$ & 4 & 5 & 7 & \\
\hline
\end{tabular}

\subsection{Marshall test}

At each gradation and aggregate type, Marshall test specimens of $101.6 \mathrm{~mm}$ diameter and $63.5 \mathrm{~mm}$ thick were prepared as per AASHTO T245-82 by varying bitumen content to study the effect of aggregate type and gradation on the behavior of bituminous mixes. The specimens were then subjected to specific gravity, stability, and flow tests as Marshall mix design procedure. For determination of optimum bitumen content (OBC), the variations of bulk density, Marshall stability flow values and voids in total mix with bitumen contents were plotted and shown in Fig. 2, Fig.3, Fig.4 and Fig.5 respectively. At optimum bitumen content, the values of bulk density, Marshall stability, flow, percentage of voids in total mix (Va, \%), percentage of voids in mineral aggregates (VMA, \%), percentage of voids filled with bitumen and Marshall stiffness for different gradation types using are shown in Table (4-a, 4-b, and 4-c). 
JES, Assiut University, Faculty of Engineering, Vol. 42, No. 3, May2014, pp. 567-574

Table 4. a.

Properties of mixes at optimum bitumen content for lime stone aggregate

\begin{tabular}{|l|l|l|l|}
\hline \multirow{2}{*}{$\begin{array}{l}\text { PROPERTY OF ASPHALT CONCERT } \\
\text { MIXTURES }\end{array}$} & \multicolumn{3}{|l|}{ AGGTRGATE GRADATION TYPE } \\
\cline { 2 - 4 } & $\begin{array}{l}\text { Fine } \\
\text { gradation }\end{array}$ & $\begin{array}{l}\text { Medium } \\
\text { gradation }\end{array}$ & $\begin{array}{l}\text { Coarse } \\
\text { gradation }\end{array}$ \\
\hline Optimum binder content (\%) & 5.4 & 5.2 & 5.0 \\
\hline Marshall stability (kgf) & 1150 & 1380 & 1440 \\
\hline \multicolumn{1}{|c|}{ Specific gravity (gm/ $\left.{ }^{3}\right)$} & 2.384 & 2.399 & 2.413 \\
\hline Air voids (\%) & 4.5 & 4.0 & 3.5 \\
\hline Marshall flow (mm) & 3.65 & 3.88 & 3.94 \\
\hline Voids in mineral aggregates (\%) & 14.7 & 14.2 & 13.45 \\
\hline VFB, \% & 74.2 & 74.1 & 72.2 \\
\hline Marshall stiffness, kgf/mm & 308.21 & 355.67 & 365.48 \\
\hline
\end{tabular}

Table 4. b.

Properties of mixes at optimum bitumen content for dolomite aggregate

\begin{tabular}{|l|l|l|l|}
\hline \multirow{2}{*}{$\begin{array}{l}\text { PROPERTY OF ASPHALT CONCERT } \\
\text { MIXTURES }\end{array}$} & $\begin{array}{c}\text { AGGTRGATE GRADATION TYPE } \\
\text { gradation. }\end{array}$ & $\begin{array}{c}\text { Medium } \\
\text { Agg. } \\
\text { gradation }\end{array}$ & $\begin{array}{c}\text { Coarse Agg. } \\
\text { gradation }\end{array}$ \\
\hline Optimum binder content (\%) & 5.2 & 5.0 & 4.80 \\
\hline Marshall stability (kgf) ( & 1480 & 1420 & 1407 \\
\hline \multicolumn{1}{|c|}{ Specific gravity (gm/c $\left.{ }^{3}\right)$} & 2.46 & 2.47 & 2.45 \\
\hline Air voids (\%) & 3.8 & 3.8 & 4.1 \\
\hline Marshall flow (mm) & 3.65 & 3.6 & 3.3 \\
\hline Voids in mineral aggregates ( \% V.M.A) & 15.5 & 14.8 & 15.8 \\
\hline VFB, \% & 74.2 & 74.1 & 72.2 \\
\hline Marshall stiffness, kf/mm & 405 & 394 & 426 \\
\hline
\end{tabular}

Table 4. c.

Properties of mixes at optimum bitumen content for basalt aggregate

\begin{tabular}{|c|c|c|c|}
\hline \multirow[b]{2}{*}{$\begin{array}{l}\text { PROPERTY OF ASPHALT CONCERT } \\
\text { MIXTURES }\end{array}$} & \multicolumn{3}{|c|}{ AGGTRGATE GRADATION TYPE } \\
\hline & $\begin{array}{c}\text { Fine Agg. } \\
\text { gradation }\end{array}$ & $\begin{array}{c}\text { Medium } \\
\text { Agg. } \\
\text { gradation }\end{array}$ & $\begin{array}{c}\text { Coarse Agg. } \\
\text { gradation }\end{array}$ \\
\hline Optimum binder content (\%) & 5.0 & 4.8 & 4.6 \\
\hline Marshall stability (kgf) & 1400 & 1380 & 1330 \\
\hline Specific gravity $\left(\mathrm{gm} / \mathrm{c}^{3}\right)$ & 2.384 & 2.399 & 2.413 \\
\hline Air voids $(\%)$ & 4.5 & 4.0 & 3.5 \\
\hline Marshall flow (mm) & 3.65 & 3.48 & 3.01 \\
\hline Voids in mineral aggregates $(\%)$ & 14.7 & 14.2 & 13.45 \\
\hline $\mathrm{VFB}, \%$ & 74.2 & 74.1 & 72.2 \\
\hline Marshall stiffness, $\mathrm{kf} / \mathrm{mm}$ & 383 & 397 & 441 \\
\hline
\end{tabular}




\section{Results and discussions}

\subsection{Analysis of Marshall test results}

The test data from Marshal Test were analyzed to identify the effect of aggregate type and gradation variation. Analysis examines the variation of the different mixture parameter (i.e., air voids, VMA, stability, flow, density, and Marshall Stiffness). Tables (4-a), (4-b), (4-c) were prepared to compare the results of mixture parameters for all three gradation bands.

The mixture with fine gradation band has the highest stability and the coarse one has the lowest. Also asphalt mixture with fine gradation band has the highest flow parameter and also the coarse one has the minimum of flow parameter in three gradation bands. Furthermore, the mixture with coarse gradation band has the lowest special gravity but it has the highest amount of air voids and VMA. The middle gradation mixture has the lowest air voids percentage and VMA but it has the highest special gravity.

Considering aggregate type, it's found that Marshall Stability is higher for lime stone while the basalt one is the lower, while Marshall Stiffness is higher for basalt and lower for lime stone aggregate.

\section{Conclusions}

Experimental program was designed and conducted on common asphalt paving mixtures of different aggregate types and gradations.

On the basis of experimental results of this investigation the following conclusions are drawn:

1. The effects of Course aggregate gradation, on the behavior of bituminous mixes is reasonably good from the considerations of Marshall test properties.

2. For better stiffness and to deformation of the bituminous mix at higher temperatures, Course gradation can be used as coarse aggregates in bituminous mixes.

3. The highest value of stability was achieved by Limestone aggregate with gradation $4 \mathrm{C}$ and the lowest value was achieved by Basalt aggregate of gradation $2 \mathrm{C}$. Basalt mix of coarse gradation had the highest value of flow and lime stone of gradation fine had the lowest value

4. Course gradation of asphalt mixture design shows the best performance against flow while fine one has the highest amount of deformation.

\section{REFERENCES}

[1] (ASTM, 2003). Annual Book of ASTM Standards. Volume 04.03

[2] Brown, E.R., McRae, J. and Crawley, A., Effect of aggregate on performance of bituminous concrete, ASTM STP, 1016: 34-63 (1989).

[3] Ahlrich, R.C. (1996). Influence of Aggregate Gradation and Particle Shape/Texture on Permanent Deformation of Hot Mix Asphalt Pavements, Army Engineer Waterways Experiment Station Vicksburg MS Geotechnical Lab.

[4] Button, J.W., Perdomo, D., and Lytton, R.L. (1990). Influence of Aggregate on Rutting in Asphalt Concrete Pavements, Transportation Research Board.

[5] Stakston, A.D., and Bahia, H. (2003). The Effect of Fine Aggregate Angularity, Asphalt Content and Performance Graded Asphalts on Hot Mix Asphalt Performance, University of Wisconsin - Madison, Department of Civil and Environmental Engineering, Submitted to Wisconsin Department of Transportation, Division of Transportation Infrastructure 
Development, Research Coordination Section, WisDOT Highway Research Study 0092-4598.

[6] Gandhi, P. and Lytton, R., Evaluation of aggregates for acceptance in asphalt paving mixtures, Proceedings of The Association of Asphalt Paving Technologists, 53: 525-558 (1984).

[7] Bissada A F, (1984). "Resistance to compaction of asphalt paving mixtures and its relationship to stiffness." ASTM STP 829, USA.

[8] Bose S, (2001). "Development of design procedure for bituminous macadam mixes for roads and highways. Highways Res Bull, No. 65, 93-102.

[9] Rashid Geotechnical\& Materials Engineers, Evaluation of quarry and aggregate crusher of the Uoited Company for Maintenance and Contracting in Wadi Laban, Technical Report, Project No. 880698 (In Arabic) pp. 1-12 (1988).

[10] El-Basyouny, M.M. and Mamlouk, M.S (1999), Effect of aggregate gradation on rutting potential of Superpave mixes, Paper presented at 78th annual meeting of the Transportation Research Board, Washington D.C.

[11] Krutz, N.C., and Sebaaly, P.E. (1993). The Effects of Aggregate Gradation on Permanent Deformation of Asphalt Concrete, AAPT. 


\section{تأثير تدرج الركام على اداء الخلطة الاسفلتية الساخنة}

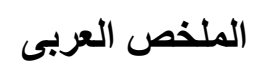

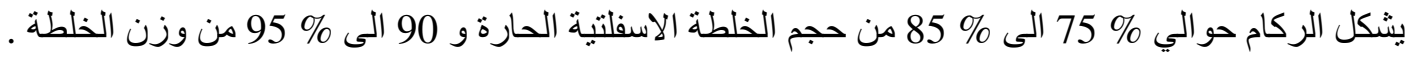

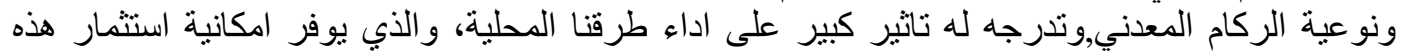

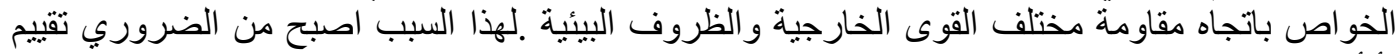

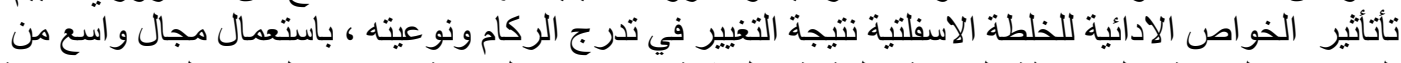

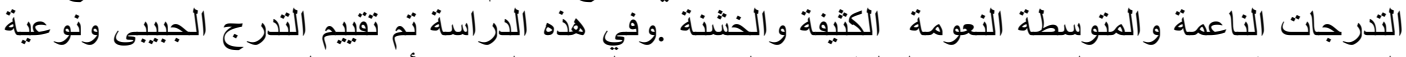

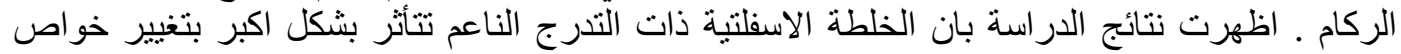

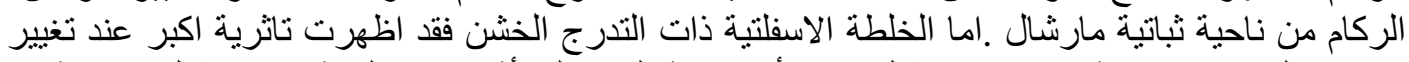

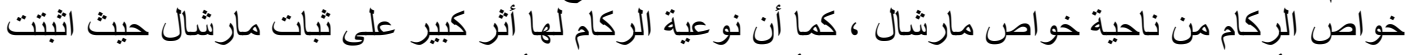

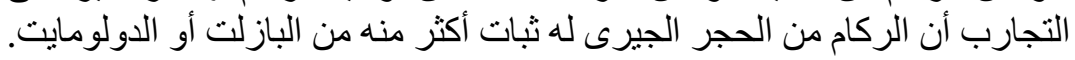

